\title{
ARGUMENTACIÓN Y PUNTOS DE VISTA EVIDENCIALES CITATIVOS: ACERCA DE LA NEGACIÓN METADISCURSIVA EN EL DISCURSO POLÍTICO
}

\author{
María Marta GARcía Negroni \\ Universidad de San Andrés - Universidad de Buenos Aires / CONICET
}

\section{RESUMEN}

En este trabajo, y en el marco del Enfoque dialógico de la argumentación y la polifonía, se analizan los puntos de vista evidenciales citativos vehiculizados por la negación metadiscursiva en un corpus de discursos pronunciados por diferentes políticos argentinos. El objetivo es doble: por un lado, se busca poner de manifiesto que, en estos casos, la enunciación negativa queda presentada como desencadenada por marcos de discurso (i. e., encadenamientos argumentativos que se presentan como el origen de la enunciación) relativos a un decir ajeno -previo o prefigurado-. Por el otro, que en respuesta dialógica a esos marcos de discurso sobre los que se funda la enunciación queda configurado un cierto posicionamiento de L (el locutor en tanto tal) y, con él, un cierto ethos (Ducrot 1984; Amossy 1999). Ligados a diferentes escenas de enunciación política y moldeados en relación con los distintos destinatarios (Maingueneau 1999), se diferencian así el ethos de la confrontación y la descalificación, el didáctico, el de la humildad, el defensivo preocupado por el resguardo de la propia imagen y el de cercanía.

PALABRAS CLAVE: argumentación, ethos, negación metadiscursiva, puntos de vista evidenciales citativos.

\section{AbSTRACT}

In line with the Dialogical Approach to Argumentation and Polyphony, in this paper, I focus on the quotative evidential points of view expressed through metadiscursive negation in a corpus of political speeches given by various Argentine politicians. My goal is twofold. On one hand, I try to show that, in these cases, the negative enunciation is presented as triggered by discourse frames related to previous or potential speeches, i.e., by argumentative chains presented as the origin of the enunciation. On the other, I aim to prove that in a dialogical reply to those discourse frames, on which enunciation is based, a certain positioning of the speaker is built, together with a certain ethos (Ducrot 1984; Amossy 1999). Considering different scenographies (Maingueneau 1999) in political enunciation, which are adjusted according to the different addressees, I make a distinction 
between the confrontation, pedagogical, humbleness, self-defense (concerned with preserving one's image and equality) and closeness ethos.

KEYWORDS: argumentation, ethos, metadiscursive negation, quotative evidential points of view.

Fecha de recepción: 02/04/2018

Fecha de aceptación: 01/05/2018

Fecha de la versión definitiva: 03/05/2018

\section{INTRODUCCIÓN}

Como se recordará, en el marco de su teoría polifónica de la enunciación, Ducrot distingue tres tipos de negaciones: la descriptiva, la polémica y la metalingüística. Mientras que la primera es analizada como un derivado delocutivo de la polémica y permite «representar un estado de cosas, sin que su autor presente su palabra como opuesta a un discurso adverso» (Ducrot 1984: 216-217), la negación polémica siempre supone la presencia de dos puntos de vista antagónicos e internos al propio discurso. Dichos puntos de vista son atribuidos a distintos seres discursivos, los enunciadores $\mathrm{E}_{1}$ y $\mathrm{E}_{2}$ : el primero es el responsable del punto de vista positivo subyacente, el segundo constituye el rechazo del primero y representa la perspectiva con la que el locutor se homologa (Ducrot 1984; Nølke 1992). Esta negación tiene siempre un efecto descendente ( $i$. e., su lectura es 'menos que'), conserva los presupuestos del enunciado positivo subyacente y su función es la de permitir una representación asertiva de la situación. En cuanto a la negación metalingüística, Ducrot la caracteriza como una negación que contradice los términos mismos de una palabra efectiva que se pretende refutar, por lo que siempre opone dos locutores diferentes. Para el lingüista francés, es justamente en el marco de esta refutación de un locutor adverso que la negación adquiere ciertas características particulares, a saber:

a) puede anular las presuposiciones del enunciado positivo previo;

b) puede tener, «en lugar de su efecto habitualmente 'reductor', un valor ascendente» (Ducrot 1984: 217).

Así, según Ducrot, «se puede decir 'Pedro no es inteligente, es genial', pero solo en respuesta a alguien que efectivamente calificó a Pedro de inteligente» (1984: 217):

(1) A: -Pedro es inteligente.

B: - No, no es inteligente. Es genial.

Ahora bien, tal como argumenté en trabajos previos (García Negroni, 2009, 2016a), este último tipo de negación no comparte con la negación 
polémica su efecto «descendente»o «reductor»: su presencia habilita las lecturas 'contrario de' (No, no es inteligente. Es tonto), 'diferente de' (No, no es inteligente. Es astuto) o 'más de' (No, no es inteligente. Es genial). Tampoco es necesario que contradiga los términos mismos de una palabra efectiva previa. En efecto, si esto es así en su empleo metalingüístico propiamente dicho, es decir, en aquellos casos en los que la negación cuestiona el empleo de un término o de un grupo de palabras del interlocutor en virtud de una regla sintáctica, morfológica, social, etc., que es puesta en evidencia por el enunciado posterior que introduce la rectificación, no ocurre necesariamente lo mismo cuando de lo que se trata es de su empleo metadiscursivo. Así, por ejemplo, en (2), la refutación no concierne al discurso de un interlocutor efectivo previo, sino a la representación surgida de un discurso evocado dialógicamente en la propia enunciación negativa descalificadora:

(2) No podemos, en modo alguno, aceptar un intento extorsivo de esta naturaleza. Nos lo impide la ética, nos lo impide nuestra conciencia democrática, las normas constitucionales, así como las que rigen las Fuerzas Armadas, basadas en la disciplina... También nos lo impide la historia, de la que los argentinos hemos extraído una clara enseñanza: ceder ante un planteamiento semejante sólo significa poner en juego el destino de la Nación.

Entonces, aquí no hay nada que negociar. La democracia de los argentinos no se negocia. Se terminó para siempre el tiempo de los golpes, pero también se terminó el tiempo de las presiones, los pronunciamientos y los planteos.

(Fragmento del discurso de R. Alfonsín ante el Congreso de la Nación, 16/4/1987. Disponible en <http://www.historiaydoctrinadelaucr.com/ 2014/02/raul-alfonsin-mensaje-al-congreso.html>) ${ }^{1}$.

En este trabajo, me detendré en este tipo de negaciones metadiscursivas en un corpus constituido por discursos pronunciados por diferentes líderes políticos argentinos. Mi objetivo será doble. Por un lado, buscaré poner en evidencia que, en estos casos, la enunciación negativa queda presentada como desencadenada por un marco de discurso relativo a voces ajenas previas o prefiguradas, esto es, por encadenamientos argumentativos que se presentan como el lugar a partir del cual surge la enunciación. En otras palabras, argumentaré que la negación metadiscursiva vehiculiza puntos de vista (de aquí en más PdV) evidenciales citativos que exigen la identificación de esos encadenamientos argumentativos previos causantes de la

\footnotetext{
${ }^{1}$ El ejemplo (2) constituye un fragmento del discurso pronunciado por el entonces presidente Raúl Alfonsín en ocasión del primer levantamiento «carapintada» contra el orden constitucional en la Semana Santa de 1987.
} 
enunciación y que, según el locutor, no corresponden a la caracterización discursiva de la situación. La caracterización del significado evidencial que propondré buscará así poner de manifiesto los lazos semánticos que existen entre ese tipo de significados y los distintos modos en los que queda representada la causa de la enunciación. Por otro lado, intentaré mostrar que, en respuesta dialógica a esos marcos de discurso sobre los que se funda la enunciación negativa, queda configurado un cierto posicionamiento del locutor y, con él, un cierto ethos (Ducrot 1984; Amossy 1999). Ligados a diferentes escenografías (Maingueneau 1999, 2002) de la enunciación política y moldeados en relación con los distintos destinatarios, los ethos que el análisis permitirá distinguir serán el de la confrontación y la descalificación, el pedagógico, el de la humildad, el defensivo preocupado por el resguardo de la propia imagen y el de cercanía.

El trabajo se organiza como sigue. En primer lugar, introduzco los fundamentos teórico-metodológicos del Enfoque dialógico de la argumentación y de la polifonía (García Negroni 2016a, 2016b, 2016c, en prensa; García Negroni y Libenson 2015, 2016), en el que se sustenta mi investigación, y en ese marco propongo una aproximación al dominio evidencial. En particular, me refiero a los PdV evidenciales y a cómo ellos contribuyen al sentido del discurso y a la configuración dialógica de la (inter)subjetividad (\$2). A continuación, me detengo en el estudio de los PdV evidenciales citativos vehiculizados por las negaciones metadiscursivas y en la identificación de los distintos ethos configurados en la enunciación política (\$3). Finalmente, en el último apartado (\$4), presento las conclusiones del estudio.

\section{El ENFOQUE DIALÓGICO DE LA ARGUMENTACIÓN Y LA POLIFONÍA Y SIGNIFICADO EVIDENCIAL}

\subsection{Marco teórico-metodológico}

En la senda trazada por las teorías de la polifonía enunciativa y de la argumentación lingüística (Ducrot 1986, 2004; Carel y Ducrot 2005), el Enfoque dialógico de la argumentación y de la polifonía (de aquí en más, EDAP) adopta el principio según el cual el sentido del enunciado puede ser descripto como una calificación que el enunciado ofrece de su propia enunciación y no como el supuesto reflejo de la intención de un sujeto hablante real, dueño de su decir. En otras palabras, el EDAP sostiene que en la enunciación se expresan PdV que no tienen por qué ser atribuidos a un mismo y único sujeto que, consciente y voluntariamente, los pondría en escena. Siguiendo a Ducrot, el EDAP cuestiona así el postulado de la unicidad del sujeto hablante, según el cual para un enunciado hay un único sujeto, es 
decir, un único individuo que es, a la vez, el responsable de las actividades psicofisiológicas de las que depende la producción del enunciado y el responsable de todo cuanto en él se comunica. En su lugar, plantea la existencia de una polifonía enunciativa en la que se distinguen las figuras discursivas del locutor (el responsable de la enunciación según el enunciado) y de los enunciadores (los distintos PdV que se expresan en la enunciación y respecto de los cuales el locutor adopta distintos posicionamientos enunciativos: identificación, distanciamiento, rechazo, etc.). Dentro de la categoría de locutor, el EDAP mantiene asimismo la distinción ducrotiana entre el locutor en tanto tal (de aquí en más L) y el locutor en tanto ser del mundo (de aquí en más $\lambda$ ). Recuérdese aquí que si el primero (L) es el responsable de la enunciación según el enunciado, $i$. e., el locutor considerado únicamente en su compromiso enunciativo y por lo tanto la figura con la que se relaciona la categoría del ethos, el segundo $(\lambda)$ es aquel a quien remiten las marcas de primera persona y de quien se habla en el enunciado que contiene dichas marcas ${ }^{2}$. Finalmente, el EDAP también retoma la idea de que los distintos puntos de vista que quedan plasmados en el enunciado se presentan bajo la forma de encadenamientos argumentativos, ya normativos, ya transgresivos (Carel y Ducrot 2005). En el primer caso, esos encadenamientos aparecen articulados por conectores conclusivos del tipo de por lo tanto, si... entonces, porque, en consecuencia, etc. (abr. PLT); en el segundo, por conectores concesivos del tipo de sin embargo, a pesar de que, aunque, etc. (abr. SE).

Ahora bien, para el EDAP la inserción de los enunciados en la cadena discursiva también repercute en la construcción del sentido y de la (inter)subjetividad. Por ello, a la luz del dialogismo bajtiniano, que, como se recordará, refiere a las relaciones que todo enunciado mantiene con los producidos anteriormente así como con los potenciales enunciados futuros que puedan llegar a aparecer en respuesta a él (Bajtín 1982: 281-285), el EDAP analiza el enunciado en su condición de respuesta o de anticipación de discursos frente a los cuales siempre queda constituido dialógicamente un posicionamiento subjetivo. De este modo, a las instrucciones polifónicas descriptas por Ducrot que obligan al interpretante del enunciado a localizar al (o a los) responsable(s) de la enunciación (i.e., el locutor en tanto tal), a reconocer los $\mathrm{PdV}$ introducidos en ella y a determinar la actitud que L toma respecto de ellos, el EDAP propone incorporar las relativas a otro tipo de PdV -entre ellos, los evidenciales y los alusivos-, que se relacionan con los aspectos dialógicos del sentido (García Negroni, en prensa).

\footnotetext{
${ }^{2}$ Ducrot (1984: 202) ilustra la diferencia entre estas dos imágenes del locutor en relación con el problema de los performativos explícitos. Así, respecto de la fórmula je souhaite (deseo), Ducrot explica que no es en tanto locutor L que se experimenta el deseo, sino en tanto ser del mundo, de modo que $\mathrm{L}$ realiza el acto de deseo asertando que $\lambda$ desea.
} 


\subsection{Puntos de vista evidenciales}

Aquí me detendré, en particular, en los PdV evidenciales, cuyas instrucciones dialógico-causales obligan a recuperar marcos de discurso previos que se muestran como la causa de (parte de) la enunciación en la que esos PdV se expresan. La perspectiva dialógica desde la que busco aportar a la descripción del significado evidencial se aparta así de varios de los presupuestos a los que en general se adscribe en los estudios sobre evidencialidad $^{3}$. En particular, el análisis que propone el EDAP no hace intervenir ni la categoría de sujeto hablante como origen del sentido, ni la de información como lo codificado que se transmitiría en el discurso, ni la de fuente $u$ origen empírico de esa información supuestamente transmitida, como habitualmente se plantea en los estudios sobre evidencialidad (Anderson 1986; Willet 1988; Aikhenvald 2004; Bermúdez 2005, 2016; Cornillie 2007; Rodríguez Ramalle 2008, 2014, entre otros). En efecto, para el EDAP, de lo que se trata es de dar cuenta de cómo los PdV evidenciales plasmados en el enunciado contribuyen a la representación dialógica y polifónico-argumentativa que el enunciado brinda de la causa de su propia enunciación.

Como se sabe, a diferencia de las lenguas que codifican significados evidenciales en su morfología de manera obligatoria, el español dispone de un conjunto de recursos prosódicos, morfológicos, sintácticos y léxicos que, según su aparición en empleos específicos, vehiculizan este tipo de significados. Pero ya sea que esté gramaticalizada en la lengua, ya sea que aparezca bajo la forma de recursos o estrategias evidenciales, los enunciados con marcas o PdV evidenciales ${ }^{4}$ proponen sistemáticamente una imagen de la enunciación como causada por discursos argumentativos (i.e., marcos de discurso) previos en los que una cierta representación discursiva de las

${ }^{3}$ Como es sabido, la evidencialidad suele definirse como el dominio semántico relacionado con la marcación de la fuente de información en el enunciado y con la especificación de qué tipo de fuente (directa o indirecta) se trata (Aikhenvald 2004). Se dice que la fuente es directa cuando el conocimiento de lo que el hablante dice ha sido adquirido por medio de una percepción originada en alguno de sus sentidos e indirecta cuando dicho conocimiento procede ya de una inferencia, ya de la cita de un discurso ajeno (Anderson 1986; Willet 1988). Se afirma, asimismo, que, según sea directa o indirecta, la fuente implica distintos grados de confiabilidad, los que, a su vez, repercuten sobre la actitud epistémica del hablante frente a lo que comunica (Chafe 1986; Plungian 2001; Dendale y Tasmowski 2001).

${ }_{4}$ Así, por ejemplo, en español, determinados empleos de ciertos tiempos verbales (como el condicional, el imperfecto, el futuro morfológico y el futuro perifrástico) algunos marcadores del discurso (como por lo visto, al parecer, así que, entre otros) o ciertos patrones entonativos (como el tono circunflejo) plasman PdV evidenciales. Al respecto, podrá consultarse García Negroni (2016, en prensa a, en prensa b) y García Negroni y Libenson (2016a, b) y (en prensa); Caldiz (2015). 
fuentes queda articulada normativa o transgresivamente con aserciones sobre $\lambda$ respecto de ellas ${ }^{5}$. Dicho de otro modo, las instrucciones dialógico-causales de los PdV evidenciales hacen ver la enunciación ya como motivada por encadenamientos argumentativos referidos a percepciones que la autentifican ( $i$. e., Fui testigo perceptual de X PLT puedo $(\lambda)$ dar fe de X), ya como surgida de un marco de discurso conjetural (i.e., Veo/Dicen/Se sabe $\mathrm{X}_{\mathrm{B}}$ PLT infiero $(\lambda) \mathrm{X}_{\mathrm{A}}$ ), ya como ocasionada por marcos en los que quedan establecidas distintas relaciones entre $\lambda$ y los discursos citados o evocados (i. e., Dicen $X$ SE no puedo $(\lambda)$ confirmar $X /$ Dicen $X$ PLT admito $(\lambda)$ que $X$ es posible / Dijiste $X$ SE veo $(\lambda)$ que no $X /$ Dicen $X$ SE no es asi para mi $(\lambda)$, entre otros varios posibles $)^{6}$. Por otra parte, y al igual que en el caso de los PdV descriptos por la teoría polifónica, la ocurrencia de los PdV evidenciales determina posicionamientos diversos por parte de L. Pero, aquí, esos posicionamientos deben ser interpretados como la indicación de la respuesta dialógica a los marcos de discurso sobre los que se funda la enunciación. Así, si el PdV evidencial es directo, el posicionamiento subjetivo será de fuerte compromiso; si es indirecto, en cambio, la actitud podrá ir desde la aserción precavida y cautelosa, o la concesión momentánea hasta un reproche o un rechazo enfático, según el marco de discurso evocado al que la enunciación responda.

Dicho en otros términos, los marcos de discurso que los PdV evidenciales exigen identificar explican por qué la enunciación en la que esos PdV se expresan y que responde a esos marcos previos reviste las características dialógico-causales que ella posee. En lo que sigue, y a la luz de lo hasta aquí planteado, me centraré en el estudio de las negaciones metadiscursivas en un corpus de discursos políticos. La hipótesis que trataré de demostrar es que ellas materializan PdV evidenciales citativos que obligan a buscar y a recuperar marcos de discursos previos relativos a voces ajenas consideradas erróneas o inadecuadas y frente a los cuales queda constituido un posicionamiento subjetivo de respuesta y con él un cierto ethos en la escenografía enunciativa, es decir, en el dispositivo de habla instituido por el propio discurso.

${ }^{5}$ Recuerdo que $\lambda$ corresponde al locutor en tanto ser del mundo, es decir, aquel a quien remiten las marcas de primera persona y de quien se habla en el enunciado que contiene dichas marcas. Se trata del individuo que era y que es L fuera de la enunciación de la que es el responsable.

${ }^{6}$ Para facilitar la lectura de los marcos de discurso evocados por los puntos de vista evidenciales, utilizo la variable $X$ como forma simplificada del encadenamiento argumentativo que constituye su sentido en cada caso en particular, y los subíndices A y B para aludir a cada uno de los segmentos de ese encadenamiento. 
TABLA 1. PdV evidenciales directos e indirectos

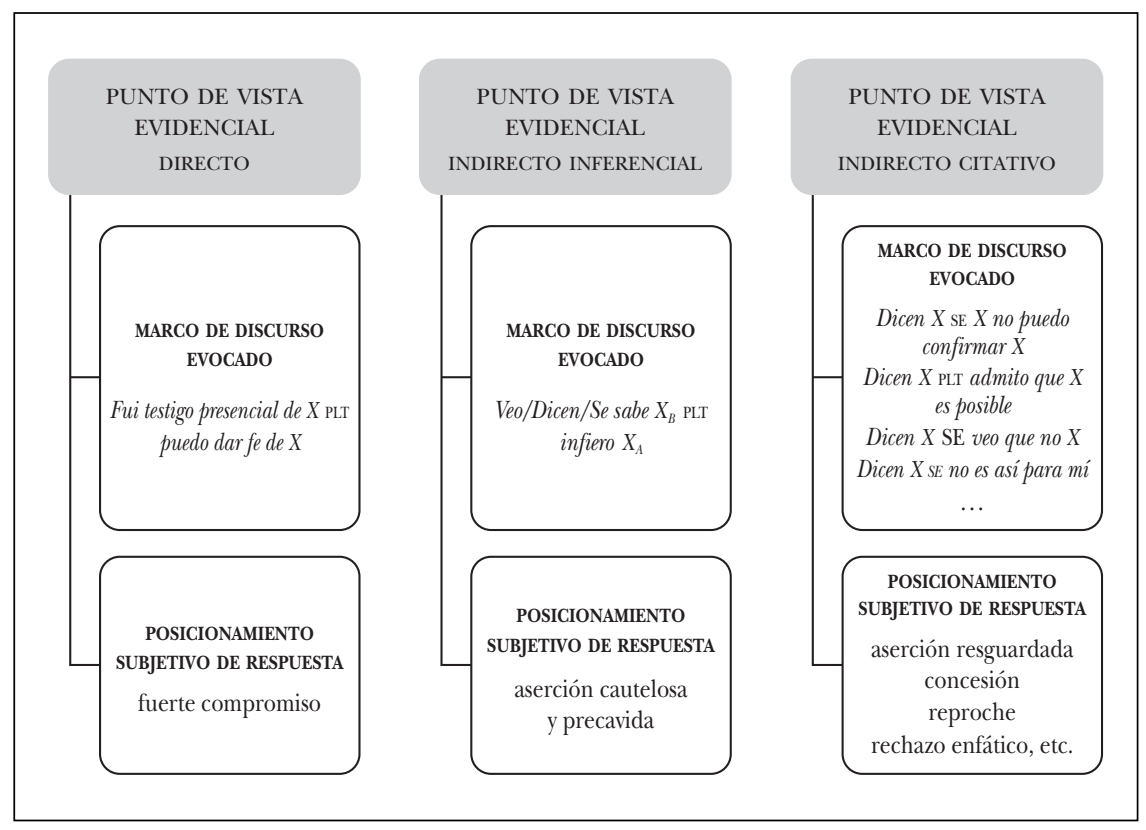

3. NEGACIONES METADISCURSIVAS, MARCOS DE DISCURSO PREVIOS, RELATIVOS A VOCES PREVIAS O PREFIGURADAS Y ETHOS

\subsection{Negación metadiscursiva y ethos confrontativo}

Como adelanté, según mi hipótesis, la negación metadiscursiva se caracteriza por plasmar PdV evidenciales citativos que exigen la identificación de un marco de discurso relativo a voces previas o prefiguradas que, según L, no corresponden a la caracterización discursiva de la situación. En otras palabras, las instrucciones semánticas asociadas a este tipo de negaciones obligan a recuperar el marco de discurso decir X SE no es así para mí, que se muestra como la causa fundante de la enunciación refutativa. Así, por ejemplo, en (2), que reitero, las negaciones codifican $\mathrm{PdV}$ evidenciales que instan a reconocer la existencia de un marco de discurso previo, relativo a voces ajenas que $\lambda$ considera insostenibles o inadecuadas, como la causa de la enunciación refutativa de $\mathrm{L}$ en la que dichos $\mathrm{PdV}$ evidenciales se expresan:

(2) No podemos, en modo alguno, aceptar un intento extorsivo de esta naturaleza. Nos lo impide la ética, nos lo impide nuestra conciencia democrática, las normas constitucionales, así como las que rigen las Fuerzas 
Armadas, basadas en la disciplina... También nos lo impide la historia, de la que los argentinos hemos extraído una clara enseñanza: ceder ante un planteamiento semejante sólo significa poner en juego el destino de la Nación.

Entonces, aquí no hay nada que negociar. La democracia de los argentinos no se negocia. Se terminó para siempre el tiempo de los golpes, pero también se terminó el tiempo de las presiones, los pronunciamientos y los planteos.

(Fragmento del discurso de R. Alfonsín ante el Congreso de la Nación, 16/4/1987. <http://www.historiaydoctrinadelaucr.com/2014/02/ raul-alfonsin-mensaje-al-congreso.html $>$ ) .

Y son esos marcos de discurso previos (representados entre corchetes), que en (2) son de la forma

(2) a. [Dicen $X_{(\text {tener las armas PIT negociación) }}$ SE no es así para mí $\left.(\lambda)\right]$

b. $\quad\left[\right.$ Dicen $\mathrm{X}_{\text {(democracia SE presión militar) }}$ SE no es así para mí $(\lambda)$ ]

los que justifican que el posicionamiento subjetivo de respuesta de total y absoluto rechazo por parte de L:

[como lo que dicen es insostenible/ilegítimo/inadecuado para mí $(\lambda)$ ], lo impugno $(\mathrm{L})$ vigorosamente $y$, en su lugar, planteo el encadenamiento argumentativo que corresponde a la situación de la que se trata.

Represento la articulación entre el marco de discurso causante de la enunciación y el posicionamiento subjetivo de respuesta mediante el conector dialógico POR LO TANTO:

[Dicen X SE no es así para mí $(\lambda)$ ]

POR LO TANTO

enunciación refutativa

(y rectificativa) de $\mathrm{L}$

Debe recordarse aquí que las enunciaciones con negaciones metadiscursivas no solo permiten mostrar, como en (2), la irrupción de un discurso $u$ otro en el interior del propio discurso, sino que además, al aparecer normalmente seguidas (con menos frecuencia, precedidas) de un enunciado de rectificación, permiten introducir el PdV con el que L quedará identificado. En el caso de (2), el enunciado de rectificación, que sigue a los encadenamientos conversos de los rechazados ${ }^{7}$, evoca el encadena-

${ }^{7}$ En términos de la semántica argumentativa (Carel y Ducrot 2005), la argumentación conversa es aquella que mantiene los dos segmentos del encadenamiento pero con cambio de conector y negación. Así, por ejemplo, las conversas de X PLT Y y de X PLT NEG. Y son, respectivamente, X SE NEG. Y y X SE Y. 
miento argumentativo democracia PLT respeto de las instituciones. La configuración global de (2) puede esquematizarse como sigue:

$$
\begin{aligned}
& \text { [Dicen } \mathrm{X}_{(\text {tener las armas PIT negociación / democracia SE presión) }} \text { SE no es así para mí }(\lambda) \text { ] } \\
& \text { POR LO TANTO } \\
& \text { enunciación refutativa de } \mathrm{L}_{\text {(tener las armas SE NEG. }} \\
& \text { negociación/ democracia PLT NEG presión) } \\
& \text { y rectificativa de } \mathrm{L}_{\text {(democracia PLT respeto de las instituciomes) }}
\end{aligned}
$$

Mostrado y no dicho, el origen del decir evocado en el marco del discurso puede resultar más o menos lejano o más o menos indeterminado. En el caso de (2), ese origen se halla en el discurso de un locutor más o menos identificable en la «memoria discursiva» (Courtine 1981). En la paráfrasis (2c), que sigue, el inciso con el marcador evidencial o mediativo como $V$ de decir $(e l+$ un) $Z$ (Anscombre 2011), permite explicitar a quién se atribuye el origen del discurso descalificado.

(2) c. Entonces, aquí no hay nada que negociar, como exigen los carapintadas. La democracia de los argentinos no se negocia, como ellos pretenden.

Y es precisamente así cómo queda construida la figura del contradestinatario indirecto del discurso y con ella el ethos (Ducrot 1984; Amossy 1999; Maingueneau 1999, 2002) de un L que, desde la posición del liderazgo político, se muestra capaz de descalificar y de refutar el decir adverso. Dicho en otras palabras, recuperar el sentido de estos enunciados negativos implica reconocer que en ellos se presentan PdV evidenciales citativos que remiten a marcos de discurso relativos a voces ajenas presentes en la memoria discursiva y que resultan fuertemente impugnadas por L. De este modo, además de los actos de aserción con los que L refuerza la creencia en los prodestinatarios y también la adhesión de los paradestinatarios (Verón 1987), el fragmento (2) configura una escenografía de fuerte confrontación en la que se realizan actos de descalificación dirigidos a los contradestinatarios indirectos del discurso (García Negroni 2016b).

Al respecto, conviene recordar que, como bien afirma Verón, a diferencia de otros tipos de discursos, el político comporta -y ello de manera constitutiva- la construcción simultánea de un destinatario positivo (el prodestinatario) y de un destinatario negativo (el contradestinatario). Mientras que el primero participa de las mismas ideas, adhiere a los mismos valores y persigue los mismos objetivos de L, el segundo es el que tiene la creencia inversa -todo lo que es verdadero o bueno para L es falso o malo para él-, el que queda excluido del colectivo de identificación y a quien le corresponde todo lo que tiene que ver con la función polémica del discurso. Verón agrega que, en el marco de las democracias contemporáneas, a menudo aparece también la figura de un «tercer hombre», el paradesti- 
natario, cuya creencia está en suspenso y al que, por tanto, se destina todo lo que es del orden de la persuasión.

\subsection{Negación metadiscursiva y ethos pedagógico}

Ahora bien, si en (2) queda configurada una escenografía agonal altamente polémica de desautorización y refutación del discurso del contradestinatario y, con ella, la figura de un L confrontativo cuyas palabras se presentan como las únicas legítimas, los $\mathrm{PdV}$ evidenciales citativos vehiculizados por las negaciones metadiscursivas pueden permitir también el surgimiento de otras escenografías y por lo tanto de otros ethos. En estos casos, y aunque también relativos a discursos previos, los marcos de discurso a los que la enunciación responde aluden a otras voces. Consideremos, en este sentido, (3):

(3) Allí estamos inaugurando una Casa de Acción Terapéutica para los jóvenes con adicciones, la casa más grande de las más de 100 casas que estamos construyendo a lo largo y a lo ancho del país para ayudar a los que tienen problemas. No hay que perseguirlos ni estigmatizarlos, hay que ayudarlos y recuperarlos.

(Fragmento del discurso de Cristina Fernández de Kirchner, 4/9/2015. Disponible en <http://www.casarosada.gob.ar/informacion/archivo/ 29016-acto-de-inauguracion-del-primer-modulo-de-la-centraltermoelectrica-de-rio-turbio-palabras-de-la-presidenta-de-la-nacion>)

Moldeado esta vez en relación con los destinatarios positivos o prodestinatarios (los militantes del propio partido), el ethos que surge en este fragmento puede caracterizarse como un ethos pedagógico o didáctico y las negaciones metadiscursivas presentes en él no son ajenas a esa constitución. En efecto, junto con otros procedimientos discursivos típicos de la secuencia expositivo-explicativa (definiciones, ejemplos, establecimiento de relaciones de causalidad, etc.), la negación de (3) permite la conformación de una escenografía profesoral (Maizels 2010), en la que queda establecida una relación asimétrica entre el responsable de la enunciación, posicionado como poseedor de un saber experto y autorizado sobre las cosas, y sus destinatarios, construidos discursivamente como discípulos a quienes se les comunica el saber en cuestión. Como puede constatarse, en esta escenografía, que construye y propone una representación inteligible de «lo real», las negaciones metadiscursivas ya no apuntan a la refutación del decir del adversario político o contradestinatario, como era el caso en (2). El marco de discurso que debe recuperarse como causa de la enunciación refutativa y al que ella responde dialógicamente alude esta vez a voces indefinidas presentadas como responsables de ciertas representaciones estereotípicas o creencias doxales, que deben ser desechadas: 


$$
\text { [Se dice } \left.\mathrm{X}_{(\text {adicción pLI persecución y estigmatización) }} \text { SE no es así para mí }(\lambda)\right]
$$

Nuevamente, la paráfrasis (3a) con el marcador evidencial o mediativo como $V$ de decir $(e l+u n) Z$ (Anscombre 2011) permite recuperar la voz colectiva a la que se atribuye el origen del discurso descalificado.

(3) a. No hay que perseguir y estigmatizar a los adictos, como algunos dicen/ piensan.

Contrarios a la propia posición discursiva (cf., en el enunciado negativo, las argumentaciones adicción SE NEG. persecución y estigmatización, conversa de la evocada en el marco de discurso desencadenante), esos principios son corregidos mediante la rectificación que sigue y que introduce el «verdadero» sentido que, desde el lugar del saber, L revela a sus interlocutores. En el caso de (3), ese sentido se expresa mediante el encadenamiento argumentativo adicción PLT ayuda y recuperación.

$$
\begin{aligned}
& \text { [Se dice/piensa } \left.\mathrm{X}_{\text {(adición PIT persecución y estigmatización) }} \text { SE no es así para mí }(\lambda)\right] \\
& \begin{aligned}
\text { POR LO TANTO } \\
\text { enunciación refutativa de } \mathrm{L}_{(\text {adicción SE NEG persecución }} \\
\text { y NEG estigmatización) }
\end{aligned} \\
& \text { y rectificativa de } \mathrm{L}_{(\text {adicción } \text { PLT ayuda y recuperación) }}
\end{aligned}
$$

\subsection{Negación metadiscursiva y ethos de la humildad}

En ocasiones, el mismo ethos pedagógico puede expresarse en negaciones metadiscursivas que rectifican el decir del propio destinatario positivo, por lo que en este caso, la enunciación responde a un marco de discurso del tipo:

[Ustedes dicen X SE no es así para mí $(\lambda)$ ]

Así ocurre, por ejemplo, en (4):

(4) Eso es el neoliberalismo: desorganizar la vida de la gente, quitarle derechos. ¿Y para qué? Algunos hablan de que hay errores de gestión o que hay mala gestión en tal área. No es un problema de mala gestión. Creo que atrás de eso se esconde el propósito de que si esto falla, en realidad fue porque no pudieron gestionar bien pero no porque las políticas sean criminales y genocidas. Y son criminales y genocidas en la medida que llevan a la gente a carecer de remedios, a carecer de acceso a tratamientos, a carecer de trabajo, a carecer de vivienda, a carecer de vida.

Yo sé que gritan «volvé» pero se trata no de que vuelva una persona, se trata de que vuelva la sociedad nuevamente empoderada, como lo estuvo en los 12 años y medio.

(Fragmento del discurso de Cristina Fernández de Kirchner, 3/12/2016. <http://www.cfkargentina.com/cristina-kirchner-en-lanus-3dic16/>) 
Pronunciado a un año de haber dejado la primera magistratura después de 12 años y medio de gobiernos sucesivos de Néstor Kirchner y Cristina Kirchner e inserto en una secuencia explicativa sobre las políticas neoliberales criminales y genocidas, con las que se alude al gobierno actual, el fragmento seleccionado contiene una estructura concesiva $p$ pero $q$, cuyo primer segmento refiere una cita en estilo directo (cf. volvé). Con ella se reconoce, dándole cuerpo en el propio discurso, la voz del prodestinatario presente en la escena de enunciación y, al hacerlo, el locutor concede el encadenamiento argumentativo que constituye el sentido de esa palabra citada:

neoliberalismo actual PLT Cristina Fernández de Kirchner tener que volver

Por su parte, en el segmento $q$ aparece la negación que, relativa al decir del prodestinatario, no apunta aquí, como en los casos anteriores, al cuestionamiento y a la anulación discursiva del discurso ajeno. Antes bien, al corregir y rectificar solo uno de los agentes de las acciones involucradas, ella reconoce como válida la relación argumentativa en PLT (i.e., normativa) entre neoliberalismo actual y tener que volver: solo se trata de cambiar «una persona» por «la sociedad empoderada», como se explicita en el enunciado de rectificación.

neoliberalismo actual PLT la sociedad empoderada tener que volver

Al servicio de un ethos pedagógico, autorizado desde el lugar del liderazgo político para explicar «lo real»y, por lo tanto, habilitado para rectificar y reorientar los sentidos en circulación, la negación de (4) permite también hacer surgir otra imagen discursiva de L. Se trata de la de un sujeto que, bajo la aparente modestia o humildad de alguien que no pretende para sí el ejercicio del poder (cf. se trata no de que vuelva una persona, es decir «la propia persona»), busca establecer con sus interlocutores un vínculo de paridad o de horizontalidad al proponer la vuelta de la sociedad nuevamente empoderada. Sin embargo, y tal como queda explicitado en el segmento como lo estuvo en los 12 años y medio, esa sociedad cuyo regreso se reclama no es otra que la del colectivo conducido por el propio liderazgo.

[Ustedes dicen $\mathrm{X}_{\text {(neoliberalismo PLT CFK tener que volver) }}$ SE no es así para mí $(\lambda)$ ] POR LO TANTO

enunciación refutativa de $\mathrm{L}_{(\text {neoliberalismo SE NEG. }}$ CFK tener que volver)

y rectificativa de $\mathrm{L}_{\text {(neoliberalismo actual } \text { PIT sociedad }}$ 


\subsection{Negación metadiscursiva y ethos defensivo y alerta}

Ahora bien, si las negaciones metadiscursivas plasman PdV evidenciales citativos, las voces ajenas evocadas en el marco de discurso al que responde la enunciación no solo pueden ser previas sino también previstas o prefiguradas. Como afirma Bajtín (1982), el enunciado es un eslabón de la cadena discursiva y, en tanto tal, no solo responde a enunciados previos, sino también, y de forma anticipada, a los enunciados que eventualmente podrían seguirlo. Es lo que puede constatarse, por ejemplo, en (5):

(5) Esto creo que además es vital que lo abordemos, por eso este encuentro, este tercer encuentro que está siendo trabajado de manera tan importante y que comenzó a ser trabajado en la ex ESMA, en el Espacio de la Memoria, y que éste es su tercer encuentro, debe ser replicado también en otras áreas. Porque la tarea de organización popular excede con creces el rol de los partidos políticos y las capacidades de los partidos políticos para reorganizar nuevamente a la sociedad. No es que esté descreyendo - en absoluto- de los partidos políticos y de las organizaciones partidarias, nada más alejado de mí, soy profundamente democrática, pero entiendo que no es suficiente.

(Fragmento del discurso de Cristina Fernández de Kirchner, 3/12/2016. <http://www.cfkargentina.com/cristina-kirchner-en-lanus-3dic16/>)

Caracterizado esta vez por la presencia del subjuntivo polémico (NGLE 2009: 1945) ${ }^{8}$ en la expresión negativa explicativa con el verbo ser en su empleo impersonal no es que (cf. no es que esté descreyendo) ${ }^{9}$, el punto de vista evidencial citativo plasmado por esta negación obliga a identificar como causa de la enunciación que la contiene un marco de discurso relativo a voces eventuales:

(5) [Podría decirse/pensarse $\mathrm{X}_{\text {(proponer CFK organización popular } \mathrm{PLT} \text { descreer CFK de partidos politicos) }}$ SE nO es así para mí $(\lambda)]$

En esta escenografía profesoral, en la que la enunciación refutativa se muestra causada por un marco de discurso relativo a cuestionamientos posibles a la alocución en curso, surge un ethos defensivo, receloso y preocupado por el resguardo de la propia imagen. Alerta frente a interpretaciones posibles no deseadas, se despliega así la imagen discursiva de alguien que busca dominar y controlar el sentido y anular, de este modo, eventuales

\footnotetext{
${ }^{8}$ Según la NGLE, este uso del subjuntivo polémico "reproduce para contradecirla o desestimarla alguna afirmación previa" (2009: 1945).

${ }^{9}$ Según indica la NGLE, la expresión es que "se antepone en el registro coloquial a oraciones que introducen justificaciones (unas veces aclaraciones y otras excusas o disculpas) relativas a lo que se declara en el discurso precedente" (2009: 3003).
} 
discursos críticos. Obsérvese al respecto la presencia de los refuerzos en absoluto y nada más alejado de mí, que con vehemencia descartan el encadenamiento argumentativo impugnado, para luego rectificarlo, sobre la base de la argumentación conversa:

(5) [Podría decirse/pensarse $\mathrm{X}_{\text {(proponer CFK organización popular PIT descreer CFK de partidos politicos) }}$ SE nO es así para mí $(\lambda)]$

\author{
POR LO TANTO \\ enunciación refutativa de $\mathrm{L}_{\text {(proponer CFK organización }}$ \\ popular SE NEG. descreer CFK de partidos políticos) \\ y rectificativa de $\mathrm{L}_{\text {(CFK profundamente democrática SE NEG. }}$ \\ bastar partidos políticos y organizaciones partidarias)
}

En algunos casos, esos eventuales discursos críticos descartados anticipadamente pueden ser atribuidos al contradestinatario, como en el fragmento siguiente, en el que el ethos defensivo se funde con el ethos confrontativo:

(6) Compañeros y compañeras: quisiera poder contarles de la mejor manera, lo que siento en este momento. Verlos a ustedes me hace recordar parte de la historia de mi propia vida y también la de nuestro país. Déjenme decirles que siento una sana envidia por todos ustedes. Pero no por lo que seguramente alguno mañana va a decir «claro, querría tener 20 años, por eso se hace la nena». No, quéva. ¿Saben por qué les tengo envidia? Porque cuando yo fui joven como ustedes, cuando junto a miles y millones de argentinos apostábamos a un país diferente, no tuvimos la suerte que tienen ustedes hoy de vivir en un país con todas las libertades.

(Fragmento del discurso de Cristina Fernández de Kirchner, 14/12/2010. $<$ https://soydondenopienso.wordpress.com/2010/09/16/ cristina-no-en-su-caracter-de-presidenta-sino-de-militantehabla-a-los-jovenes-en-el-luna-parkkkkkkkkk/>)

Varios elementos (cf. la interpelación directa mediante vocativos o mediante el pronombre objeto de 2..$^{\text {a }}$ persona plural -compañeros y compañeras; verlos a ustedes-, los verbos de decir-contarles, decirles-, la pregunta -i Saben por qué?- y el tono emotivo e íntimo) permiten la construcción en (6) de una escenografía dialogal de mucha cercanía, en la que la locutora se dirige a sus prodestinatarios como si fuera una amiga que les habla de sus sentimientos más personales, en este caso, los relacionados con los recuerdos de su propia juventud militante. En esta escenografía, queda plasmado, nuevamente en una estructura explicativa (pero no por lo que alguno va a decir mañana), un PdV evidencial citativo vehiculizado por la negación. Esta vez, dicho PdV exige interpretar la enunciación refutativa que lo contiene como causada por un marco de discurso relativo a voces eventuales atribuidas al otro negativo (i.e., Ellos van a decir X SE no es así para mi $(\lambda)$ ). Y es precisamente ese marco de discurso el que permite dar cuenta del posicionamien- 
to subjetivo de total y absoluto rechazo (cf. el refuerzo que sigue No, qué va) seguido de la rectificación que introduce el propio $\mathrm{PdV}$ presentado como el único que corresponde a la situación de la que se trata. Esquemáticamente, la negación de (6), en la que la configuración de la propia imagen discursiva surge de un proceso de «retrabajo» de un ethos previo forjado sobre «lo que otros han dicho sobre nosotros» (Amossy 2010: 72), presenta la siguiente configuración:

$$
\begin{aligned}
& \text { [Ellos van a decir }{ }_{\text {(NEG. ser joven PII tener envidia de la juventud) }} \text { SE no es así para mí }(\lambda) \text { ] } \\
& \text { POR LO TANTO } \\
& \text { enunciación refutativa de } \mathrm{L}_{\text {(NEG. ser joven SE NEG. tener }} \\
& \text { envidia de la juventud) } \\
& \text { y rectificativa de } \mathrm{L}
\end{aligned}
$$

Ahora bien, la enunciación negativa de (6) no solo constituye una respuesta anticipada que permite el surgimiento de una figura que confronta con ese otro y descalifica burlonamente su decir. Al aludir mediante alguno va a decir mañana a la "corporación mediática», blanco privilegiado de los discursos de la expresidenta Kirchner, sobre todo a partir del conflicto con el campo en 2008, la locutora pone en juego un lazo de un saber compartido ( $i$. e., la relación problemática entre la prensa y la entonces presidenta) con sus prodestinatarios. Y es ese lazo de saber compartido el que permite, a su vez, el establecimiento de un vínculo de fuerte solidaridad con el prodestinatario que reconoce esa remisión como parte de la «memoria» del discurso kirchnerista. Dicho de otro modo, al funcionar como recuerdo de discursos previos y al actualizar en el presente de la enunciación los sentidos de esas formulaciones anteriores, el segmento pero no por lo que alguno va a decir mañana permite reafirmar el pacto de complicidad intersubjetiva entre locutor y prodestinatarios. Así, al quedar configurados como partícipes del mismo grupo que comparte el conocimiento de aquello a lo que se alude ${ }^{10}$, los lugares simbólicos que L se otorga a sí mismo y a sus prodestinatarios refuerzan la escena de habla íntima y cómplice y, con ella, el ethos de cercanía que le es inherente.

${ }^{10}$ En García Negroni (en prensa), me ocupo de los PdV alusivos. Fuertemente relacionados con lo que Authier-Revuz $(1984,1992)$ denomina formas de la heterogeneidad mostrada no marcada, este tipo de PdV constituyen modos de decir en los que se retoma, se transforma o se enmascara lo dicho en acontecimientos discursivos anteriores. Por cierto, en tanto no constituyen el objeto declarado de la enunciación sino un sentido aludido, estos PdV son susceptibles de ser pasados por alto. Sin embargo, y tal como afirma Authier, si son reconocidos por el interpretante funcionan a modo de recuerdo de discursos previos y habilitan el acceso a ellos. 


\section{Consideraciones finales}

A lo largo de las páginas que preceden, y en el marco del EDAP, he propuesto un abordaje del significado evidencial de las negaciones metadiscursivas en un corpus de discursos políticos de atril. Por un lado, busqué poner de manifiesto que, en estos casos, la enunciación negativa queda presentada como causada, como desencadenada por marcos de discurso relativos a voces ajenas, esto es, por encadenamientos argumentativos referidos a discursos previos o prefigurados que se presentan como el lugar a partir del cual surge la enunciación. Por el otro, intenté dar cuenta de cómo, en respuesta dialógica a esos marcos de discurso sobre los que se funda la enunciación, queda configurado un cierto posicionamiento del locutor y, con él, un cierto ethos, es decir, la «imagen de sí» proyectada en el propio discurso. Ligados a diferentes escenografías (agonales, profesorales, dialogales) y moldeados en relación con los distintos destinatarios (contradestinatarios, prodestinatarios), distinguí el ethos de la confrontación y la descalificación, el pedagógico o didáctico, el de la humildad, el defensivo preocupado por el resguardo de la propia imagen y el de cercanía.

Como ha podido constatarse, mi análisis del significado evidencial se distancia fuertemente de los presupuestos que, en general, se sostienen en los estudios sobre evidencialidad. En efecto, según el EDAP, dar cuenta del significado evidencial no consiste en describir la actividad mental de un sujeto hablante real que informaría acerca de cómo él obtuvo el conocimiento de lo que afirma, sino en caracterizar el modo en que el enunciado muestra la causa desencadenante de su enunciación y el posicionamiento subjetivo de respuesta implicado. Dicho de otro modo, según mi perspectiva, lo propio del significado evidencial no reside en identificar las percepciones, las inferencias o las citas que serían el origen empírico del conocimiento del hablante, sino en recuperar los encadenamientos argumentativos que, mostrados a través de la enunciación, construyen una determinada representación argumentativa de las percepciones, de las abducciones y de los discursos citados. En el caso de los PdV evidenciales citativos plasmados en las negaciones metadiscursivas, esos encadenamientos son del tipo

[Ellos dicen/Se dice/Ustedes dicen/Van a decir X SE no es así para mí $(\lambda)$ ]

En otras palabras, las instrucciones semánticas asociadas a este tipo de PdV evidenciales exigen identificar marcos de discurso referidos a voces ajenas, previas o prefiguradas, como fundantes de la enunciación en la que se expresan. Y dado que $\lambda$ (el individuo que L era y es fuera de su enunciación) no coincide con ellas, L (el responsable de la enunciación negativa) las impugna y rechaza:

[como lo que dicen/se dice/van a decir es insostenible/ilegítimo/inadecuado para $m i(\lambda)]$, lo impugno $(\mathrm{L})$ vigorosamente. 
En cuanto a la actitud epistémica que habitualmente se asocia al significado evidencial, he tratado de mostrar que ella no se deriva del tipo de "fuente de información», sino del posicionamiento dialógico de respuesta que queda configurado frente al marco de discurso que suscita la enunciación. En el caso de las negaciones metadiscursivas aquí analizadas, y aunque siempre de rechazo, dicho posicionamiento dialógico permite dar cuenta de los diferentes ethos que se manifiestan en la enunciación. Así, si el marco de discurso alude a voces del contradestinatario, el ethos que surge en respuesta es el confrontativo; si alude a voces doxales consideradas inadecuadas, el ethos toma las características de lo pedagógico o didáctico; si alude a las del prodestinatario, el ethos didáctico puede superponerse con el de la humildad; finalmente, si alude a voces prefiguradas, el ethos defensivo y alerta frente a sentidos no deseados quedará fundido con el confrontativo o el de cercanía. Y es que, actualizado en cada enunciación, el sentido de la refutación se vincula con el marco de discurso que la suscita (cf. Tabla 2).

TABLA 2. Negaciones metadiscursivas y ethos

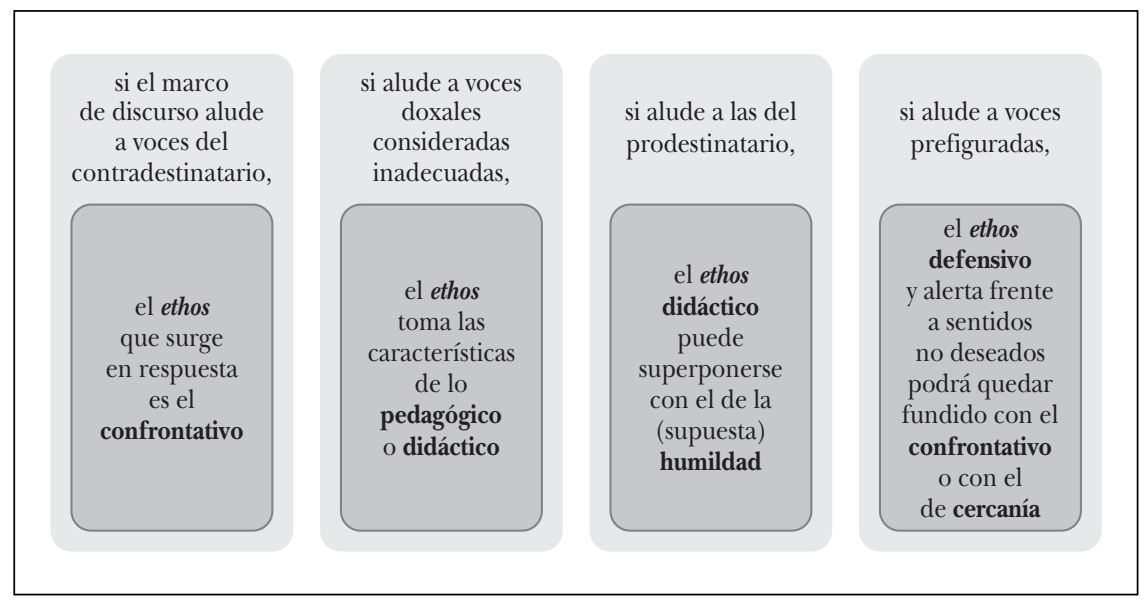

En definitiva, desde el enfoque dialógico de la argumentación y la polifonía que propongo, el sentido no solo está determinado por los PdV caracterizados por la teoría polifónica de la enunciación y el respectivo posicionamiento de L, sino también, entre otros, por los PdV evidenciales, que ponen de manifiesto la relación causal de la enunciación con otras previas y/o posteriores en la cadena discursiva. Y es por ello que el sujeto no puede ser concebido como una entidad exterior al funcionamiento del lenguaje (i. e., el hablante real), sino como una figura interna que surge de las relaciones dialógicas que manifiesta el enunciado frente a la alteridad siempre constitutiva. 


\section{BIBLIOGRAFÍA}

AikhEnvald, Alexandra (2004): Evidentiality, Oxford: Oxford University Press.

Amossy, Ruth (1999): Images de soi dans le discours. La construction de l'éthos, Lausanne/París: Delachaux et Niestlé.

- (2010): La présentation de soi. Ethos et identité verbale, París: Presses Universitaires de France.

Anderson, Lloyd (1986): «Evidencials, Paths of Change, and Mental Maps: Typologically Regular Asymmetries». En Wallace Chafe y Johanna Nichols (eds.), Evidentiality: The Linguistic Coding of Epistemology, Norwood: Ablex Publishing Corporation, 273-312.

Anscombre, Jean-Claude (2011): «L'introduction du pronom neutre dans les marqueurs médiatifs à verbe de dire de type Comme dit le proverbe / Como dice el refrán: étude sémantique contrastive d'une contrainte polyphonique», Langages 184, 13-34.

AutHIER-Revuz, Jacqueline (1984): «Hétérogénéité(s) énonciative(s)», Langages 73, 98-111.

- (1992): «Repères dans le champ du discours rapporté», L'Information Grammaticale 55, 38-42.

BajTín, Mijaíl (1982): Estética de la creación verbal, México: Siglo XXI.

BERMúdEZ, Fernando (2005): «Los tiempos verbales como marcadores evidenciales: El caso del pretérito perfecto compuesto", Estudios Filológicos 40, 165-188.

- (2016): «Rumores y otros malos hábitos. El condicional evidencial en español», Cuadernos de Lingüistica de El Colegio de México, 3/2, 35-69.

CALDIZ, Adriana (2015): «Subjetividad, prosodia y ponencias científicas. A propósito del ethos autoral surgido de la lectura en voz alta». En María Marta García Negroni (ed.), Subjetividad, alteridad y polifonía, Buenos Aires: Ampersand, 51-75.

CAREL, Marion y Oswald Ducrot (2005): La semántica argumentativa. Una introducción a la teoría de los bloques semánticos, Buenos Aires: Colihue.

CHAFE, Wallace (1986): «Evidentilality in English Conversation and Academic Writing». En Wallace Chafe y Johanna Nichols (eds.), Evidentiality. The Linguistic Coding of Epistemology, Norwood: Alex Publishing, 261-272.

CorniluIE, Bert (2007): Evidentiality and Epistemic Modality in Spanish (Semi-)Auxiliaries. A Cognitive-Functional Approach, Berlín: Mouton de Gruyter.

Courtine, Jean-Jacques (1981): «Analyse du discours politique (le discours communiste adressé aux chrétiens)», Langages 62, 9-128.

DendALE, Patrick y Liliane Tasmowsky (2001): «Introduction: Evidentiality and related notions», Journal of Pragmatics 33, 339-348.

Ducrot, Oswald (1984): Le dire et le dit, París: Minuit.

- (2004): «Sentido y argumentación». En Elvira Arnoux y María Marta García Negroni (eds.), Homenaje a Oswald Ducrot, Buenos Aires: Eudeba, 359-370.

García Negroni, María Marta (2009): «Negación y descalificación. A propósito de la negación metalingüística», Ciências e Letras 4, 61-82. 
- (2016a): «Polifonía, evidencialidad y descalificación del discurso ajeno. Acerca del significado evidencial de la negación metadiscursiva y de los marcadores de descalificación», Letras de Hoje 51/1, 7-16.

- (2016b): «Discurso político, contradestinación indirecta y puntos de vista evidenciales. La multidestinación en el discurso político revisitada», Revista ALED 16/1, 37-59.

- (2016c): «Polifonía, evidencialidad citativa y tiempos verbales. Acerca de los usos citativos del futuro morfológico y del futuro perifrástico». En R. González Ruiz, D. Izquierdo Alegría y Ó. Loureda Lamas (eds.), La evidencialidad en español: teoría y descripción, Madrid: Iberoamericana / Fráncfort del Meno: Vervuert, 279-302.

- (en prensa): «El enfoque dialógico de la argumentación y la polifonía, puntos de vista evidenciales y puntos de vista alusivos», RILCE (Revista de Filología Hispánica).

García Negroni, María Marta y Manuel Libenson (2015): «Para una descripción polifónica de la evidencialidad. Subjetividad y estructuras evidenciales con pronombres demostrativos neutros». En María Marta García Negroni (ed.), Subjetividad, alteridad y polifonía, Buenos Aires: Ampersand, 17-49.

- y - (2016): «Argumentación, evidencialidad y marcadores del discurso. El caso de por lo visto», Tópicos del Seminario 35, 51-75.

Maingueneau, Dominique (1999): «Ethos, scénographie, incorporation». En Ruth Amossy (ed.), Images de soi dans le discours. La construction de l'ethos, París: Delachaux et Niestlé, 75-102.

- (2002): «Problèmes d'éthos», Pratiques 113/114, 55-67.

MaIzels, Ana Laura (2010): «La negación en los discursos de campaña política de Cristina Fernández de Kirchner (2007)». En Actas del IV Congreso Internacional de Letras, Buenos Aires, FFyL. <http://2010.cil.filo.uba.ar/sites/2010. cil.filo.uba.ar/files/143.Maizels.pdf>.

NøLKE, Henning (1992): «Ne... pas: négation descriptive ou polémique? Contraintes formelles sur son interprétation», Langue Française 94, 48-67.

—, Kjersti Fløttum y Coco Norén (2004): Scapoline. La théorie scandinave de la polyphonie linguistique, París: Kimé.

Plungian, V. (2001): «The place of evidentiality within the universal grammatical space», Journal of Pragmatics 33, 349-358.

Real ACAdemia Española (2009): Nueva gramática de la lengua española. Madrid: Espasa.

Rodríguez Ramalle, María Teresa (2008): «Estudio sintáctico y discursivo de algunas estructuras enunciativas y citativas del español», Revista Española de Lingüistica Aplicada 21, 269-288.

- (2014): «Sobre marcadores y su relación con la modalidad evidencial». En María Marta García Negroni (ed.), Marcadores del discurso: perspectivas y contrastes, Buenos Aires: Santiago Arcos, 233-250.

VERÓn, Eliseo (1987): «La palabra adversativa. Observaciones sobre la enunciación política». En Eliseo Verón (ed.), El discurso político. Lenguajes y acontecimientos, Buenos Aires: Hachette, 1-12.

WILLETT, Thomas (1988): «A cross-linguistic survey of the grammaticalization of evidentiality», Studies in Language 2, 51-97. 